\title{
Cost analysis of inappropriate treatments for suspected dermatomycoses
}

\author{
Emanuela Fiammenghi ${ }^{1}$, Angela Patalano ${ }^{1}$, Viviana Lo Conte ${ }^{1}$, Gabriella Calabrò ${ }^{1}$
}

${ }^{1}$ Department of Clinical Medicine and Surgery - Dermatology - University Hospital of Naples Federico II

\begin{abstract}
Superficial mycoses are estimated to affect more than $20-25 \%$ of the world's population with a consistent increase over the years. Most patients referred to our clinic for suspected dermatomycoses have already been treated with pharmacotherapy, without a previous mycological examination and many show changes in the clinical manifestations. Indeed, some medications, such as steroids, antiviral, antibiotics and antihistamines are not able to erase a fungal infection, but also they can cause atypical clinical manifestations.

The consequences of inappropriate treatment include delayed diagnosis, prolonged healing time, and additional costs. The aims of this study were (1) to evaluate the incidence of increased costs attributable to inappropriate therapy sustained by the National Health Service and patients and (2) to highlight the importance of mycological evaluation before starting treatment, in order to improve diagnostic accuracy. An observational retrospective and prospective study was performed from September 2013 to February 2014, in 765 patients referred to our center (University Hospital "Federico II") in Naples, Italy, for suspected mycological infection. The following treatments (alone or in combination) were defined as inappropriate: (1) cortisone in a patient with at least one positive site; (2) antifungals in (a) patients with all negative sites or (b) ineffective antifungal treatment (in terms of drug chosen, dose or duration) in those with all positive sites; or (3) antibiotics; (4) antivirals or (5) antihistamines, in patients with $\geq 1$ positive site. Five hundred and fifty patients were using medications before the assessment visit. The total amount of avoidable costs related to inappropriate previous treatments was $€ 121,417$, representing $74 \%$ of the total treatment costs. $253 / 550$ patients received drugs also after the visit. For these patients, the cost of treatment prescribed after mycological testing was $€ 42,952$, with a decrease with respect to the total consumption of drugs at the time of access to the Mycology Laboratory of $€ 34,781$.

Thus, our cost analysis shows that it is important to obtain a reduction of costs for pathologies that need to be confirmed by examinations before starting treatment.
\end{abstract}

\section{Keywords}

Cost-analysis; Inappropriate treatments; Dermatomycoses; Mycological examination

\section{INTRODUCTION}

Superficial mycoses (dermatophytosis, candidiasis and infections by non-dermatophyte molds) can affect the scalp, glabrous skin, nails and skin folds and are estimated to affect more than $20-25 \%$ of the world's population, with a consistent increase over time [1]. They often present with characteristic lesions, but can be difficult to diagnose and may be mistaken for other cutaneous disorders. Indeed their clinical manifestation can vary according to several factors, including the site of infection, immunological status of the host and the fungal species.

Thus, laboratory investigation to identify the fungus responsible for the infection is essential for correct diagnosis and management of superficial mycosis [2], since appropriate treatment can bring immediate relief and potentially produce a rapid and complete resolution of all lesions. Conversely, failure to diagnose and treat correctly can prolong the patient's suffering over considerable periods of time. Direct microscopy and culture [2] are rapid, sensitive and specific noninvasive diagnostic tests that can reveal at an affordable cost ( $€ 23.30)$ whether or not fungal infection is present.

The most frequent systemic antifungals used for treatment of superficial mycoses are griseofulvin (the "gold standard" in tinea capitis), azoles (itraconazole and fluconazole) and allylamines. Topical therapy is used in the limited forms of the infection and whenever hair or nails are not involved, and as an adjuvant to systemic therapy. Polyenes,
Corresponding author Emanuela Fiammenghi emanuelafiammenghi@libero.it

\section{Disclosure}

Study funded by Pierre

Fabre Italia S.p.A 
azoles, allylamines, hydroxypyridone such as ciclopiroxolamine, and morpholine derivatives in cream, solution, nail lacquer, and powder formulations are the most important topical agents used [3].

At the Mycology Laboratory of the University of Naples "Federico II", we see each year approximately 1,700 patients with suspected mycological infection. These patients are referred to our center by dermatologists and general practitioners (GP)s, for confirmation of the diagnosis by mycological examination. Most patients have already received pharmacological treatment without previous mycological testing. In many cases these patients have shown changes in the clinical manifestations. Some medications such as steroids, antivirals, antibiotics and antihistamines, that are not able to eradicate fungal infections, can also cause atypical clinical manifestations [4]. Indeed, the most important factor influencing the clinical appearance seems to be prolonged use of steroids, especially topical steroids [5,6].

As a result, patients may face delayed diagnosis and prolonged healing time, as well as economic impact. Where costs are reimbursed, this also has an impact on the National Health System.

\section{OBJECTIVES OF THE STUDY}

The aims of this study were:

1. to evaluate the incidence of costs attributable to inappropriate therapy sustained by the National Health Service and patients; and

2. to highlight the importance of mycological investigations before starting treatment, in order to improve diagnostic accuracy.

\section{METHODS}

An observational retrospective and prospective study was performed from September 2013 to February 2014. We enrolled all patients referred to the Mycology Laboratory of the University Hospital of Naples "Federico II" - Department of Clinical Medicine and Surgery for suspected mycological infection. Using a purpose-built database, we retrospectively checked previous pharmacological treatments taken by each patient. Active ingredient, dosage form, and prescribed dosage and duration were recorded for each treatment. At enrolment (visit) a mycological investigation was performed and results were recorded, classified by site (single site/ multiple locations). For the subset of patients who received new drug therapies after posi- tive mycological testing, prescribed therapies were recorded. For each patient and each treatment taken over time, drug consumption was recorded based on estimates of the dose according to the site of infection reported in a previous study [7].

Dosages were calculated based on the estimated number of affected locations, using an algorithm that correlates the amount of drug used (for the site) and the amount of drug contained in the package (tablets, ointments, sprays, solutions, vials) to derive the overall consumption of the active drug principle. All active principles reported were grouped according to the ATC classification. For each active principle the corresponding marketed formulation was identified and the corresponding pack price retrieved [8]. The price of treatment was calculated based on the average price per unit and usage (dosage and duration) for each drug therapy that was used for the treatment of specific locations of mycoses.

Average and total cost for the previous treatments (before-visit) and total and average cost for the treatment of patients after the positive mycological test (post-visit) were calculated.

Based on the outcome of the mycological investigation, we identified patients who had received inappropriate drug therapies prior to the visit. The following treatments, alone or in combination, were considered inappropriate:

1. cortisone prescribed to a patient with at least one positive site;

2. antifungals

- in patients with all negative sites;

- ineffective antifungal therapy in patients with all positives sites (inappropriate drug, dose or duration);

3. antibiotics in patients with at least one positive site;

4. antivirals in patients with at least one positive site; and

5. antihistamines in patients with at least one positive site.

Thus, two categories were identified:

1. patients not actually affected by mycosis but treated with antimycotic agents; and

2. patients with confirmed mycosis who were given inappropriate treatment, in terms of the active agent, the dosage or the duration.

The total cost of inappropriate prescriptions was calculated as a proportion of the total cost sustained before the hospital visit for these patients. For patients who received a drug therapy prior to the visit and were prescribed new therapies after a positive mycological test, costs were also calculated for the 


\begin{tabular}{|c|c|c|c|c|c|c|c|}
\hline \multirow{3}{*}{ ATC } & \multirow{3}{*}{ Description } & \multicolumn{6}{|c|}{ Cost } \\
\hline & & \multicolumn{2}{|c|}{ Class A } & \multicolumn{2}{|c|}{ Class C } & \multicolumn{2}{|c|}{ Total } \\
\hline & & $€$ & $\%$ & $€$ & $\%$ & $€$ & $\%$ \\
\hline $\mathrm{D}$ & Dermatological drugs & $9,565.08$ & 39.1 & $138,786.5$ & 99.8 & $148,351.62$ & 90.7 \\
\hline $\mathrm{H}$ & Systemic hormonal preparations & 666.86 & 2.7 & 0 & 0.0 & 666.86 & 0.4 \\
\hline$J$ & Anti-infective drugs for systemic use & $13,104.37$ & 53.6 & 0 & 0.0 & $13,104.37$ & 8.0 \\
\hline $\mathrm{N}$ & Nervous system drugs & 0 & 0.0 & 138.75 & 0.1 & 138.75 & 0.1 \\
\hline \multirow[t]{2}{*}{$\mathrm{R}$} & Respiratory system drugs & $1,095.57$ & 4.5 & 178.65 & 0.1 & $1,274.22$ & 0.8 \\
\hline & Total & $24,431.88$ & 100.0 & $139,103.94$ & 100.0 & $163,535.82$ & 100.0 \\
\hline
\end{tabular}

Table I. Drug cost distribution according to previous consumption classified by ATC group

treatment after the evaluation (post-visit). Additionally, the study aimed to estimate the cost borne by the patients and by the Regional Health Service for visits and examinations. To estimate costs for visits, we distinguished patients referred by a specialist from those referred by GPs. For the first group we estimated that approximately $60 \%$ of patients had a private visit (internal data from the center), while for the remaining patients an outpatient visit and a GP visit were accounted for. The cost to the Regional Health Service for a GP visit was estimated at $€ 15$ [9], while the reimbursement for a specialist dermatologic visits was estimated at $€ 20.66$ [10]. The mean cost for a private dermatologic visit was estimated to be $€ 70$ [11]. The cost for a mycological examination was estimated as $€ 23.34$ [10] for a patient without exemption and $€ 13.30$ for a patient with exemption code E05 [10], while for a patient with total exemption the cost is totally covered by the NHS [12].

\section{RESULTS}

\section{Patients}

A total of 765 patients were enrolled in the period September 2013-February 2014. Of these, $550(71.9 \%)$ reported receiving previous therapies. Their average age was 46.6 years (45.3 years for male; 47.6 years for female patients); $91.6 \%$ of patients were referred by a specialist and $8.4 \%$ by GPs; $4.7 \%$ of patients had diabetes and $24.7 \%$ had psoriasis as a concomitant disease. The body sites affected varied considerably, with nails and body infections predominating, but many patients had multiple affected sites. The scalp was most commonly affected in young patients (mean age was 14.4 years), while nail infections (with or without involving other sites), more commonly affected older patients. Mean age was significantly lower for affected scalp than affected nails (Wilcoxon test; $\mathrm{p}<0.0001)$.

\section{Treatment prior to clinic visit}

As already mentioned, drug treatments prior to the visit were recorded on the basis of the information provided by the patients themselves. The total cost of drugs was estimated at $€ 163,536$, corresponding to an average of $€ 297$ per patient. The vast majority of drugs $(85.6 \%)$ were classified as NHS reimbursement Class $\mathrm{C}$ (paid for by the patient) and ATC Class D (dermatological drugs; 90.7\%) (Table I).

Antifungals (Classes D01A+D01B+J02AC of the ATC classification) accounted for more than half of the drugs used by the patients before the specialist visit and cortisone (Classes ATC D07 and H02AB) for almost one-third. Antibiotics, antivirals and antihistamines were infrequently used, while remaining drugs were represented almost exclusively by psoriasis treatments (ATC D05AX). Drug consumption was very low for young patients and increased with age (Kruskall-Wallis test; $\mathrm{p}=0.0065$ for $\leq 18,19-64 v s \leq 65$ years); there was no difference in drug usage between male and female patients (Mann-Whitney test; $p=0.87$ ). Multiple sites of disease (body and skin folds; nail and body; nail and body with skin folds) were associated with high average consumption of drugs, although the site that most frequently required multiple drugs was nails (23.1\%) (KruskallWallis $\mathrm{p}<0.0001$ considering all sites and their combinations). Drugs were mostly used by patients referred by GPs and by patients with psoriasis (not statistically significant). It is notable that 4 drugs/drug combinations: amorolfine (12.64\%); diflucortone/isoconazole $(10.68 \%)$; calcipotriol/betamethasone $(10.50 \%)$ and gentamicin/betamethasone $(10.17 \%)$ accounted for almost half of the consumption of drugs in the "before-visit" period.

Two hundred and eighty six of the 550 patients with previous treatments $(52 \%)$ tested negative for fungal infection in single or multiple locations, while $264(48 \%)$ test- 


\begin{tabular}{|c|c|c|c|c|c|c|}
\hline \multirow{2}{*}{ Drug } & \multirow{2}{*}{ Formulation } & \multirow{2}{*}{ ATC } & \multirow{2}{*}{ MP } & \multirow{2}{*}{ Reimbursement class } & \multicolumn{2}{|c|}{ Cost } \\
\hline & & & & & $€$ & $\%$ \\
\hline Amorolfine 5\% & Nail lacquer & D01AE16 & 40.70 & C & 366.30 & 0.85 \\
\hline Ciclopirox olamine & Cream & D01AE14 & 7.62 & C & $13,896.36$ & 32.38 \\
\hline Ciclopirox olamine & Powder & D01AE14 & 8.65 & C & $3,044.80$ & 7.09 \\
\hline Ciclopirox olamine & Emulsion & D01AE14 & 8.95 & C & 125.30 & 0.29 \\
\hline Ciclopirox olamine & Nail lacquer & D01AE14 & 27.00 & C & $3,753.00$ & 8.74 \\
\hline Fluconazole $100 \mathrm{mg}$ & Tablet & J02AC01 & 28.46 & A & $18,555.92$ & 43.23 \\
\hline Griseofulvin 125 mg & Tablet & D01BA00 & 1.96 & A & 86.24 & 0.20 \\
\hline Griseofulvin 500 mg & Tablet & D01BA01 & 3.15 & A & 667.80 & 1.56 \\
\hline Itraconazole $100 \mathrm{mg}$ & Tablet & J02AC02 & 8.29 & A & $1,989.60$ & 4.64 \\
\hline Miconazole & Powder & D01AC02 & 9.03 & C & 216.72 & 0.50 \\
\hline Terbinafine 250 mg & Tablet & D01BA02 & 14.59 & A & 218.85 & 0.51 \\
\hline Total & & & & & $42,920.89$ & 100 \\
\hline
\end{tabular}

Table II. Drug cost distribution after mycological testing according to ATC category $\mathrm{MP}=$ Market Price

\begin{tabular}{lccc}
\hline \multicolumn{1}{c}{ Description } & ATC & \multicolumn{2}{c}{ Total cost } \\
\cline { 3 - 4 } & & $\boldsymbol{\epsilon}$ & \% \\
\hline $\begin{array}{l}\text { Antifungals in patients with } \\
\text { all negative sites }\end{array}$ & D01A+D01B+J02AC & $51,182.54$ & 42.15 \\
$\begin{array}{l}\text { Antifungals in patients } \\
\text { with all positive sites } \\
\text { (inappropriate drug, dose }\end{array}$ & D01A+D01B+J02AC & $38,057.13$ & 34.34 \\
or duration) & & & \\
$\begin{array}{l}\text { Cortisone in patients with } \\
\geq 1 \text { positive site }\end{array}$ & D07+H02AB & $28,338.25$ & 23.44 \\
$\begin{array}{l}\text { Antibiotics in patients with } \\
\geq 1 \text { positive site } \\
\text { Antivirals in patients with }\end{array}$ & D03BA+D06A+J01 & $2,968.01$ & 2.44 \\
$\geq 1$ positive site & D06B+J05 & 27.80 & 0.02 \\
$\begin{array}{l}\text { Antihistamines in patients } \\
\text { with } \geq 1 \text { positive site }\end{array}$ & R06 & 843.27 & 0.69 \\
\begin{tabular}{l} 
Total \\
\hline
\end{tabular} & & $\mathbf{1 2 1 , 4 1 7}$ & $\mathbf{1 0 0}$ \\
\hline
\end{tabular}

Table III. Inappropriate costs for drugs according to ATC categories

ed positive in at least one locations; 238 (43.3\%) tested positive in single or multiple locations.

Of the 550 patients who had received drug therapy before the visit, 253 were found to be positive for mycosis and were prescribed drug therapies after the visit. The remaining 297 patients were referred to other diagnostic-therapeutic pathways. For the 253 patients taking medications both before and after the visit to the specialist center, the total cost of drugs before the visit was estimated to be $€ 77,733.42$ corresponding to $€ 307.25$ per capita, with female patients accounting for a higher proportion of cases $(64.03 \%)$ and total $(72.4 \%)$ and average $(+47.39 \%$ with respect of males) consumption (Mann-Whitney test; $\mathrm{p}=0.59$; not statistically significant).

\section{Consumption of drugs after the visit}

For the 253 patients prescribed drugs after mycological testing, the cost of the prescribed drugs amounted to a total of $€ 42,920.89$ (Table II), corresponding to $€ 169.65$ per capita. The reported cost for treatments after the visit was significantly lower in younger than in older patients (Kruskall-Wallis test; $\mathrm{p}<0.0001$ for $\leq 18,19-64$ versus $\geq 65$ years). Infections involving nails were associated with the highest treatment costs (KruskallWallis test; $p<0.0001)$. No significantly statistically differences in costs were reported in classes based on immunodeficiency or concomitant diseases. For all patients, the costs for previous treatment (from the onset of the disease to enrolment) were significantly higher than costs for the post-visit period (Wilcoxon paired test; $p=0.028$ ).

\section{Cost for inappropriate treatments}

The total cost of the therapies used by the patients before the assessment visit was $€ 163,536$, with inappropriate treatments accounting for $€ 121,417$ (Table III).

For the 253 patients who were prescribed new treatments after completion of mycological testing, the total amount of avoidable costs for inappropriate previous treatments was $€ 65,30827$, while the cost of appropriate treatment prescribed after the visit and mycological testing was $€ 42,921$. For patients who tested negative for cutaneous mycoses, the cost of treatment post-examination was not calculated, as they were referred for further diagnosis, but the total cost of their previous antifungal therapy was approximately $€ 51,182$ (mean cost $€ 178$ ) (statistical data to be reckoned with). 


\section{Cost for visits and testing}

Considering all of the 765 patients analyzed, the total cost borne by the regional healthcare service for the specialist or GP public visits was $€ 9,995.36$, while the cost sustained by the patients for private visits was $€ 29,431.08$. Ninety-five percent of patients were totally exempt, so the total cost borne by the regional healthcare service for the mycological visit and testing was $€ 16,933.28$. The remaining patients (5\%), to whom copayment applied, paid a total of $€$ 891.23.

\section{DISCUSSION}

A treatment is considered appropriate when there is clear evidence to support its use for the given indication, it is well tolerated and has a favorable cost-effectiveness profile [13]. Inappropriate prescribing also includes the use of drugs with incorrect duration, drug interactions and duplications [14]. Avoiding inappropriate treatments is very important for cost-containment programs within health services.

The mycology unit of our institution has had a service agreement with the national health system for approximately forty years. Recently we have seen an increased number of patients presenting with suspected mycoses that have already been treated with protracted systemic and/or topical drug therapy without laboratory confirmation of infection. Too often a diagnosis of skin mycosis (scalp, body, folds, and nails) is made based on clinical observation alone and this can lead to misdiagnosis and inappropriate treatment. As well as cost implications, inappropriate treatment can mask the fungal infection [15-19]. Moreover, systemic antifungal therapy can have serious consequences when prescribed to certain patient groups, e.g. those with comorbidities or who are immunocompromised or elderly, who may have impaired metabolism of these drugs [20].

Thus, it is important to confirm the diagnosis with a simple microscopic examination and culture. This can hasten healing and improve the quality of life of the patient, while avoiding inappropriate costs to the national health system and patient [21]. Many studies have explored the potential to avoid unnecessary costs resulting from inappropriate therapy [22-24], but this is the first that focuses on mycotic skin infections and cost savings that can be achieved by first conducting mycological examinations.

In our study, $550(71.9 \%)$ of 765 enrolled patients were using medications before the assessment visit. The total cost of these therapies was $€ 163,536$, with inappropriate treatments accounting for $€ 121,417$. Therefore, our findings indicate that $74 \%$ of the total cost borne by the NHS and the patients related to inappropriate treatments before the visit to our clinic could have been avoided if all prescriptions were optimal.

For the 253 patients who were prescribed new treatments after completion of mycological testing, the total amount of avoidable costs for inappropriate previous treatments represented $84 \%$ ( $€ 65,30827$ out of $€ 77,733.42)$ of the total cost borne by the NHS and the patients, while the cost of appropriate treatment prescribed after the visit and mycological testing was $€ 42,921$, with a decrease with respect to the total consumption of drugs at the time of access to the Mycology Laboratory of $€ 34,813$.

The vast majority of drugs consumed are classified as NHS reimbursement Class C $(86 \%)$ and more than half of the drugs used by the patients before the specialist visit were antifungals (Classes D01A+D01B+J02AC of the ATC classification), in particular amorolfine nail lacquer, and almost one-third were topical cortisone (alone or in combination). These data highlight the high incidence of self-medication by the patient with drugs available at the pharmacy without prescription.

Almost all of our patients who had already undergone therapy, were referred by a specialist dermatologist after failure of previous therapies (92\%). Thus, it would be useful to encourage specialists to send patients for mycological testing in the first instance, rather than trying therapies that could prove inappropriate.

\section{CONCLUSIONS}

This analysis illustrates the need to reduce healthcare costs arising from inappropriate treatments. In the setting of suspected mycological infections, testing is inexpensive, non-invasive, and has a short waiting time (maximum 15 days). It is important to note that our results are from a single region of Italy (Campania) and generalizability to the entire Italian population may be limited. 


\section{REFERENCES}

1. Havlickova B, Czaika VA, Friedrich M. Epidemiological trends in skin mycoses worldwide. Mycoses $2008 ; 51$ Suppl 4: 2-15; http://dx.doi.org/10.1111/j.1439-0507.2008.01606.x

2. Feuilhade de Chauvin M. New diagnostic techniques. J Eur Acad Dermatol Venereol 2005; 19 Suppl 1: 20-4; http:// dx.doi.org/10.1111/j.1468-3083.2005.01287.x

3. SIDeMaST. Micosi superficiali: linee guida e raccomandazioni SIDeMaST 2014. Available at http://www.sidemast. org/blog/micosi-superficiali-linee-guida-e-raccomandazioni-sidemast-2014 (last accessed April 2015)

4. Janković A, Binić I, Gligorijević J, et al. Mimicking each other: psoriasis with tinea incognito. Dermatologica Sinica 2011; 29: 149; http://dx.doi.org/10.1016/j.dsi.2011.09.020

5. Romano C, Maritati E, Gianni C. Tinea incognito in Italy: a 15-year survey. Mycoses 2006; 49: 383-7; http://dx.doi. org/10.1111/j.1439-0507.2006.01251.X

6. Atzori L, Pau M, Aste N, et al. Dermatophyte infections mimicking other skin diseases: a 154-person case survey of tinea atypica in the district of Cagliari (Italy). Int J Dermatol 2012; 51: 410-5; http://dx.doi.org/10.1111/j.13654632.2011.05049.x

7. Finlay AY, Long CC. The finger-tip unit-a new practical measure. Clin Exp Dermatol 1991; 16: 444-7; http://dx.doi. org/10.1111/j.1365-2230.1991.tb01232.x

8. 2014: Handbook Pharmaceutical/Database Federfarma

9. Accordo collettivo nazionale per la disciplina dei rapporti con i medici di medicina generale ai sensi dell'art. $8 \mathrm{DL}$ 512 e successive modificazioni ed integrazioni, anno 2010

10. Regione Campania. Bollettino ufficiale della regione Campania. Available at http://burc.regione.campania.it (last accessed April 2015)

11. iDoctors. Prestazioni e prezzi medi nelle regioni indicate. Available at http://www.idoctors.it/medici_specialisti/ dermatologia-e-venereologia-6 (last accessed April 2015)

12. Regione Campania. Bollettino ufficiale della regione Campania. Decreto n. 61 del 26.09.2011. Available at http:// burc.regione.campania.it/eBurcWeb/publicContent/archivio/archivio.iface (last accessed April 2015)

13. Lu YC, Ross-Degnan D, Soumerai SB, et al. Interventions designed to improve the quality and efficiency of medication use in managed care: a critical review of the literature - 2001-2007. BMC Health Serv Res 2008; 8: 75; http:// dx.doi.org/10.1186/1472-6963-8-75

14. Galván Banqueri M, Alfaro Lara ER, Rincón Gómez M, et al. Factors related with the appropriateness of pharmacological treatment in polypathological patients. Farm Hosp 2014; 38: 405-10

15. Tan Y, Lin L, Feng P, et al. Dermatophytosis caused by Trichophyton rubrum mimicking syphilid: a case report and review of literature. Mycoses 2014; 57: 312-5; http://dx.doi.org/10.1111/myc.12153

16. Ruiz Rivero J, Mendoza Cembranos MD, Ciudad Blanco MC. Ti-a incógnita: serie de casos y revisión bibliográfica. Piel 2014; 29: 624

17. Sun PL, Ho HT, Concentric rings: an unusual presentation of tinea corporis caused by Microsporum gypseum. Mycoses 2006; 49: 150-1; http://dx.doi.org/10.1111/j.1439-0507.2006.01204.X

18. Urbina F, Sudy E, Barrios M. Ti-a incógnita. Piel 2002; 17: 12; http://dx.doi.org/10.1016/S0213-9251(02)72525-2

19. Zisova LG, Dobrev HP, Tchernev G, et al. Tinea atypica: report of nine cases. Wien Med Wochenschr 2013; 163: 549-55; http://dx.doi.org/10.1007/s10354-013-0230-4

20. Pérez Fuentes MF, Castillo Castillo R, Rodríguez Toquero J, et al. Adecuación del tratamiento farmacológico en población anciana polimedicada. Medicina de Familia 2002; 1: 23-8

21. Shorr AF, MIcek ST, Kollef MH. Inappropriate therapy for methicillin-resistant Stalhylococcus aureus: resource utilization and cost implications. Crit Care Med 2008; 36: 2335-40; http://dx.doi.org/10.1097/CCM.0b013e31818103ea

22. van Walraven C, Naylor CD. Do we know what inappropriate laboratory utilization is? A systematic review of laboratory clinical audits. JAMA 1998; 280: 550-8; http://dx.doi.org/10.1001/jama.280.6.550

23. Arnold HM, Micek ST, Shorr AF, et al. Hospital resource utilization and costs of inappropriate treatment of candidemia. Pharmacotherapy 2010; 30: 361-8; http://dx.doi.org/10.1592/phco.30.4.361

24. Ojeniran M, Shouval R, Miskin IN, et al. Costs of appropriate and inappropriate use of antibiotics in the emergency department. Isr Med Assoc J 2010; 12: 742-6 